\title{
10. Myths and Music of Futuna, Vanuatu: Past and Present in Dialogue
}

\author{
Janet Dixon Keller and Takaronga Kuautonga
}

I wish to speak to a book project entitled Nokonofo Kitea/We Keep on Living This Way. Taking its title from the opening line of a customary Futuna song, the project aims to present, translate and understand aspects of the wisdom of Futuna elders and ancestors as embodied in traditional lore. ${ }^{1}$ The goals of the volume are twofold: first to challenge the idea of a narrative archive as a static repository of past knowledge with the idea that collections of narrative constitute resources for dialogue and negotiation of both past and present; and second to discuss the Futuna theory of narrative meaning as one path to dialogue.

I note first that this is a collaborative project co-authored by Takaronga Kuautonga who has taken a lead in retelling oral narratives in written form in ways we hope will be accessible to the people of Futuna familiar with the stories, to young people from Futuna who may be less familiar with them, to the people of Vanuatu more generally in their search for lines of connection across communities, and even for those from outside Vanuatu who have much to learn from local kastoms. The work has been a collaboration since the 1970s when islanders first helped me to acquire some of the traditional narrative and musical repertoires. Popoina Magau has been a long term advisor for over 30 years, assisting in transcription and translation again and again. Numerous elders and community members have contributed wisdom, wit and biting commentary through their narrative versions and interpretive discussions. I think especially of Napause Teifisou and Naparau Naora who opened my ears to furi fesao or turned words so that I could hear the messages. Some who helped with this project are no longer with us and perhaps the book to come can be a tribute to their memory. ${ }^{2}$ I think especially of Iawoi Sore, Vaega Liji and Liji Sore, of Teikona Nuaita, Breisa Tamalua, Naparau Naora, Napause Teifisou and Nawali Sore. Some have criticised the work as it developed and their critiques have helped us to improve.

\footnotetext{
1 This article draws on jointly authored work and grows out of collaborative reflection. It was originally written and delivered by the first author and reflects her perspective. The second author followed this presentation with his own oral commentary and both of us engaged the original audience in dialogue to follow (which explains the use here of first the person singular in what is acknowledged as a jointly authored paper (editors' note)).

2 The Keller and Kuautonga work, Nokonofo Kitea: We Keep On Living This Way (2007), is now available in published form through Crawford House Publishing, Belair and the University of Hawai'i Press, Honolulu.
} 
This project is oriented by Futuna theories of meaning and metaphor. We begin from the perspective that stories are structured by ata and hkano. Ata, the surface words of tellings, lead listeners to hkano, deeper meanings derived from ancestral wisdom. This dynamic means that telling (and singing as well) are ways of cueing listeners to important understandings. Listeners, themselves, must reason from the spoken cues to realise hidden significances. Such reasoning can be a process of thinking to one's self, but it can also involve conversation and negotiation over meanings. Such processes of reflection essential to the understanding of any Futuna narrative, insure that a collection of tales and songs from the island, or possibly from any ni-Vanuatu community, must combine words, spoken or sung, with dialogues of their audiences.

In addition, people of Futuna recognise that stories are told in a moment and cues vary as tellers adapt to current purposes. The same tale or lyrics may cue an audience toward one set of meanings in one context while being elaborated to cue listeners to different messages in another. As the Western cultural psychologist, Jerome Bruner, argues 'the impetus to narrative is expectation gone awry' (2002: 28). When troubles or novelties emerge new stories may be told, and familiar tales may be reshaped to address the unanticipated. Transformations of the familiar are interesting for these have the potential to articulate enduring values with unpredicted developments. In such re-tellings, narrators have the power to restore order to the narrated world by reconstructing principles from myth and kastom. Such resolutions, by extension, may cue listeners to novel perspectives on real world problems. However, neither the author nor the text dictates possibilities, it is those who listen to narrative who must grasp connections and make relevant inferences. It is in discussions among audience members from where insight must emerge and applications to the present develop.

The process of collaboration for Nokonofo Kitea: We Keep on Living this Way builds on this core perspective to join in a critique of common Western approaches to oral literatures (Bauman and Briggs 2003) by pointing out that establishing written collections as national or community archives - is a process that stifles the cultural negotiation of meaning that should occur with storytelling and musical interpretation. With Takaronga we have indeed produced a written collection, yet we have done so with the expectation that the text will engender dialogue. The volume includes dialogues that surrounded narratives we recorded and later wrote down. These conversations are critical to interpretation as speakers index events and experiences in a dynamic process of uncovering the unsaid (Basso 1996; Kulick 1992; Tyler 1978), but they are not the last word. Dialogue promotes dialogue in a process that should stir still more (re)assessment with time.

Nokonofo Kitea takes up a notion of 'reaccentuation' from the Russian scholar Mikhail Bakhtin (1989), to elaborate on the Futuna ideas regarding 
interpretation. 'Reaccentuation' recognises that the process of talking together to assess meaning implies that written collections of oral literatures can maintain and promote 'fluid and context-specific' cultural processes required for establishing relevance and importance over time in a manner that mirrors kastom talk (Regenvanu 2005). A text, whether spoken or written, is only half of a story or song. The other half resides in listeners' reflections. As long as people continue to read, perform out loud, and transform the words of a written document to address new circumstances, a collection stays alive and grows in the ever changing present (Goldman and Ballard 1998).

A native Hawaiian navigator, Nainoa Thompson, who has been involved in a reconstruction of Pacific canoes and navigational voyaging, argued to other islanders participating in one project: 'A culture does not remain alive unless it is practiced. To keep your voyaging tradition alive, you have to keep sailing' (Finney 2003: 53). Building a canoe is a start, but it is not enough to keep traditional wisdom alive. In the same way customary narratives can be constructed as oral or written texts, but in order to stay alive they need to be practised - spoken, performed, discussed, critiqued, and transformed (Micarelli and Gomez 2002). I offer some examples here of the lively interpretation of Futuna tales witnessed during the building of the Nokonofo Kitea collection. These interpretations are a part of what is written there, ano pito, bits and pieces, of the creative dialogues that surround these narratives and should continue to grow and serve as inspiration for new roads addressing community heritage and national independence, conservation and waste, modernity and the dilemmas created by globalisation.

I start with a great myth (Bonnemaison 1994) of Majihjiki and the Pasiesi. For those of you who might not know him, Majihjiki is a culture hero and trickster. Pasiesi are monsters, goblins that inhabit the hinterland of Futuna. The great myth is an ancient tale harkening from at least the nineteenth century. But it is also an allegory for today. In this story Pasiesi sets out to rid the land of its human occupants so that it will be his alone. Majihjiki's intervention allows the survivors to escape the monster's hold, eventually dispatch him, and to resettle the land recreating an original circuit of villages. Majihjiki's stated aim is to recreate the excitement and hum of human interaction that rests on independent individuals, couples, or villages interdependently enmeshed in reciprocal social exchange.

The story is told as a fantastic series of events with characters of mythical proportions who do mythical things - searching for lost children, for example, from an upside down posture. But it can be read as a critique of individual autonomy, gluttony, and selfish excess - dangerous behaviours of real situations today as in the past. This critique is articulated in arena after arena by members of the Futuna community. To start somewhere, take the Western and Christian 
ethic of forgiveness. In a community that is unquestionably Christian, Futuna voices still point out the need for shaping this idea to local norms of respect, encompassing both notions within local cultural logic. Christianity it is said is niVanuatu. The values and norms of Christianity precede its religious introduction from the West. Yet the foreign forms in which it is returned to the islands may threaten local life ways. Forgiveness applied without limit undermines the mosaic of interdependence among people of an island community - the very mosaic of reciprocity that Majihjiki aimed to recreate. It is the Pasiesi's lack of respect, a respect that would by custom be demonstrated in asking permission for the harvesting of fruit or the use of land, that threatens to destroy island life as much as his literally murderous acts. If 'stealing what belongs to others' can be forgiven, how will the orders of kinship, age and leadership that maintain community persevere? The Majihjiki story is a starting point for just this discussion.

The Pasiesi himself might be seen as modern life, an evil ogre who disrupts contentment and sociality, for self interest. One who devours everything. The consequence, if he has his way, is the destruction of community. But this destruction can be overcome by the logic of tufa, gift giving, and vaea, sharing, among simultaneously independent and interdependent villagers. Such logic builds on the arrangement of villages and neighbourhoods established as separate residential sites but in proximity to one another-often in a circle that facilitates mutual support and exchange. Modernity and urbanisation, as pasiesi, destroy that logic replacing it with single individuals who compete for and then hoard wealth, while residence is transformed into a landscape that scatters citizens across space, isolating community members from one another. Again the Majihjiki story encourages reflection on such transformations asking the listener to envision ways to keep community alive even as modernity progresses.

Another story is referred to in Nokonofo Kitea as Majihjiki and Fafine Tonga and it is about women from afar who fly to Futuna to swim in the clear waters at Sinou. Majihjiki appears here as a trickster who hides a woman's wings so that she might stay with him as his wife. Together they have a child, but Majihjiki's own trickery becomes a stumbling block as his wife discovers the hidden wings and returns home to her own island. The tale raises questions about honesty and it poses the dilemma of homesickness when one lives far from one's homeland. Also questioned and not resolved are issues of residence - should women live with their husbands' families or should men live with the families of their wives? How should a couple decide? Majihjiki eventually takes his son and follows his wife and they continue to have children and raise a family far from Majihjiki's home. Successfully so; and as the generations pass one son, Jiverau, returns to find a Futunese bride, Sina, who in another tale leaves her Futuna 
homeland to live with her husband. What might be learned from these tales about the blessings and heartaches of interisland marriages? How might they help to assuage the pain of border crossings today and celebrate the openings for exchange introduced by coming to know maivaka, strangers, from other places?

This story too creates another talking point. Similar tales are frequently told in Vanuatu (Bonnemaison 1994; Jolly 1999; Thieberger 2000). In each case episodes and events differ but some elements are shared. Discussions of the possibilities for understanding commonalities of heritage that bind together peoples of Vanuatu might focus on comparisons that would yield shared cultural values as well as contrasting modes of reason. Such discussions might contribute to debates on kastom and national identity by suggesting that kastoms may offer both common ground and signs of community differences, simultaneously posing ways to think about foundations for ni-Vanuatu identity as well as the uniqueness of individual communities (cf. Tonkinson 1982).

A final example might be taken from a song about lobster trapping, najehji, a fantastic activity to be sure that engages all of the senses, strengths, and patience of the trapper to provide for family, for community and perhaps even to offer a tribute to the heavens. But in a Futuna song najehji becomes furi fesao (metaphor) and is used to characterise nineteenth-century evangelical missions. In this nineteenth-century song, a local voice hidden in the language of lobster trapping speaks to the dangers of being caught by foreign ideological traps. Again the issue of respect arises as the singer invites the interlopers to learn the wisdom of his land of Futuna. The situation with evangelism is very different today, but perhaps the caution urging a wariness of foreign ideas is still relevant as Vanuatu negotiates an international presence, yet aims to avoid the traps set by foreign politicians and developers. How are such traps to be recognised? How avoided? Is capture by foreign entreaty ever acceptable, and if so, when? These are some puzzles the najehji song might offer for consideration.

And in each retelling, each discussion, some new wisdom may become apparent. Tradition is at its best when it inspires a new song, a new story, or a new insight that wrestles with novel circumstances while keeping the tradition alive not only in the words of the past but in the processes for shaping new allegories and musical lyrics that open conversations about contemporary situations. A new public building, the spread or cure of foreign disease, and election results are the kinds of events that Futuna narrative can celebrate, ratify or lament leading one to puzzle over or clarify the present.

These insights, emerging from the collaborative processes resulting in and, we hope, continuing beyond Nokonofo Kitea, resonate with other discourses of custom and nation current in Vanuatu (Regenvanu 2005). Our hope is 
that narrative heritage may have the potential to open roads for productive engagements within communities, and across communities, and thereby play a role in envisioning the future of the republic.

Rather than narratives serving as icons of the past, as Western scholars have often heralded folklore, the Futuna tales can be seen to represent dynamic wisdom offering insight into community values, contemporary circumstances of migration, urban life, and international relations. This heritage offers niVanuatu ways to challenge and reshape modernity and rethink the dilemmas created by globalisation. Whether as the foundation for a parent's instruction to a child on the right ways of living, a chiefly edict to resolve a conflict, a lesson in a classroom, or a sermon, these narratives can convey valued principles and generate productive discussion. The narratives can participate in a cyclic dialogism as they constitute resources from which new lifeways can be patterned while those new lifeways inspire still more narratives addressing constantly emerging ways of life. The narratives are a tradition that is in flux. What is written, in this hybrid Futuna-Western view, is neither authoritative nor fixed, but a custom resource that may be strategically employed, rewritten or retold, and transformed as occasions require, as politics demand, or as people desire. In this way the past informs the present and offers those engaged in dialogue surrounding narrative a resource for envisioning a continually evolving future.

\section{References}

Bakhtin, Mikhail M., 1989. The Dialogic Imagination, ed. Michael Holquist, trans. Caryl Emerson and Michael Holquist. Austin: University of Texas Press.

Basso, Keith H., 1996. Wisdom Sits in Places: Landscape and Language among the Western Apache. Albuquerque: University of New Mexico Press.

Bauman, Richard and Charles Briggs, 2003. Voices of Modernity: Language Ideologies and the Politics of Inequality. Cambridge: Cambridge University Press.

Bonnemaison, Joël, 1994. The Tree and the Canoe: History and Ethnogeography of Tanna. Honolulu: University of Hawai'i Press.

Bruner, Jerome, 2002. Making Stories: Law, Literature, Life. Cambridge: Harvard University Press.

Finney, Ben, 2003. Sailing in the Wake of the Ancestors. Honolulu: Bishop Museum Press. 
Goldman, Laurence R. and Chris Ballard, 1998. Fluid Ontologies: Myth, Ritual and Philosophy in the Highlands of Papua New Guinea. Westport, Conn: Bergin and Garvey.

Jolly, Margaret, 1999. Another time, another place. Oceania 69(4): 282-300.

Keller, Janet Dixon and Takaronga Kuautonga, 2007. Nokonofo Kitea: We Keep On Living This Way. Myths \& Music of Futuna, Vanuatu. Belair, Australia: Crawford House Publishing and Honolulu: University of Hawai'i Press.

Kulick, Don, 1992. Language Shift and Cultural Reproduction: Socialization, Self and Syncretism in a Papua New Guinean Village. Cambridge: Cambridge University Press.

Micarelli, Giovanna and Hernan Gomez, 2002. The Body of Memory: Theater Anthropology as a Tool for Cultural and Linguistic Reaffirmation in Indigenous Amazonia. Proceedings of the Sixth FEL Conference. R. McKenna Brown.

Regenvanu, Ralph, 2005. The changing face of 'custom'. Vanuatu people and culture. People and Culture inOceania 20: 37-50.

Thieberger, Nicholas, 2000. Walking to Erro. Paper presented to a crossdisciplinary conference: Walking About: Travel, Trade, Migration and Movement in Vanuatu. Canberra: The Australian National University.

Tonkinson, Robert, 1982. National identity and the problem of kastom in Vanuatu. Mankind 13: 306-15.

Tyler, Stephen A., 1978. The Said and the Unsaid: Mind, Meaning, and Culture. New York: Academic Press. 